\title{
Chemical and Microbial Hydrolysis of Sweet Sorghum Bagasse for Ethanol Production
}

\author{
Anusith Thanapimmetha ${ }^{1,2}$, Korsuk Vuttibunchon ${ }^{1}$, Maythee Saisriyoot ${ }^{1,2}$, Penjit \\ Srinophakun ${ }^{1,2 *}$ \\ ${ }^{1}$ Bioprocess Laboratory, Department of Chemical Engineering, Faculty of Engineering, Kasetsart University, \\ 50 Ngamwongwan Road, Jatujak, Bangkok 10900, Thailand \\ ${ }^{2}$ Thailand and The Center of Excellence for Petroleum, Petrochemicals and Advanced Materials, S\&T \\ Postgraduate Education and Research Development Office (PERDO), Thailand. \\ * Corresponding author. Tel: +662942-8555 ext. 1234 or 1203, Fax: +662561-4621, E-mail: fengpjs@ku.ac
}

\begin{abstract}
Sweet sorghum (Sorghum bicolor L. Moench) is the potential raw material of ethanol production. As a lignocellulosic material, hydrolysis is needed to transform it to sugar. Usually, this sugar was used as substrate for ethanol production by fermentation. In this study, the composition of sweet sorghum bagasse was analyzed. The compositions of the sweet sorghum bagasse before hydrolysis are $58.23 \%$ cellulose, $25.42 \%$ hemicellulose and $14.95 \%$ lignin. It was then cut, dried and pretreated at $121{ }^{\circ} \mathrm{C}, 25 \mathrm{~min}$ by sodium hydroxide. Then the experimental design is performed to design the experimental runs. Box-Behnken was used to design the experiment of chemical hydrolysis. The factors of sulfuric acid concentration $(15-55 \% \mathrm{w} / \mathrm{w})$, solid to liquid ratio (1:10-1:30 w:w) and reaction time (40-120 minutes) affecting reducing sugar production were optimized for the chemical hydrolysis. At the optimum condition, the maximum reducing sugar was equal to $33.49 \%$ ( $\mathrm{g} / \mathrm{g}$ dry substrate). On the other hand, microbial hydrolysis with Trichoderma harzianum gave the maximum reducing sugar of $10.34 \%$ (g/g dry substrate) at optimum condition. Then type of reducing sugar was analyzed using High Performance Liquid Chromatography (HPLC). It is obvious that glucose is the dominated reducing sugar. Finally, the reducing sugar (glucose, xylose and arabinose) from chemical and microbial hydrolysis is usually fermented with Saccharomyces cerevisiae to produce ethanol.
\end{abstract}

Keywords: Hydrolysis, Sweet Sorghum Bagasse, Ethanol, Trichoderma harzianum

\section{Introduction}

Sweet sorghum (Sorghum bicolor L. Moench) is a renewable, cheap, widely available resource. It is used as an alternative material for ethanol production since it is high biomass and sugar yielding crop. It contains soluble (glucose and sucrose) and insoluble carbohydrates (cellulose and hemicellulose) [1]. The juice extracting from the fresh stem is easily converted to ethanol. The remaining solid residue (bagasse) is a byproduct representing about $30 \%$ of the whole plant fresh weight. Bagasse, an important residue from sweet sorghum processing, could become an important biomass source for saccharification and fermentation for bioethanol production in the near future.

Sweet sorghum bagasse which is lignocellulosic biomass is mainly composed of cellulose, hemicellulose and lignin. Cellulose is a linear polymer that is composed of glucose subunits linked by $\beta-1,4$ glycosidic bonds. These long chains linked together by hydrogen bonds and van der Waals forces. Cellulose is usually present as a crystalline form while a small amount of nonorganized cellulose chains forms amorphous cellulose. Hemicellulose is a polysaccharide with a lower molecular weight than cellulose. Hemicellulose contains xylose, mannose, galactose, glucose, arabinose and glucuronic acids, and are linked together by $\beta$ $1,4-$ and sometimes by $\beta$-1,3-glycosidic bonds. Lignin is physical seal of hemicellulose and cellulose, which is an impenetrable barrier in the plant cell wall [2]. In order to obtain sugar, it is necessary to degrade the polymers to monomer, which can be done by physical, chemical or biological methods. 
Generally, the chemical used in the hydrolysis is sulfuric acid. Acids can breakdown the heterocyclic bonds between sugar monomers in polymeric chain, which are formed by hemicellulose and cellulose [3].

For microbial hydrolysis, numerous bacterial and filamentous fungi can produce cellulolytic enzyme such as cellulase and hemicellulase. One of the most extensively studied of cellulolytic microorganism is Trichoderma spp., which is also industrially used for enzyme production.

The aim of this work was to determine the optimum conditions for reducing sugar production from sweet sorghum bagasse by acid hydrolysis comparing with Trichoderma harzianum hydrolysis. In this experiment, three factors were optimized namely acid concentration, solid to liquid ratio and reaction time. Response Surface Methodology (RSM) using Box-Behnken Design (BBD) was applied for optimizing these independent variables.

\section{Methodology}

\subsection{Microorganisms}

The fungal strain Trichoderma harzianum, was obtained from Uniseeds Co., LTD. The inoculum of T. harzianum was in powder form and contained $10^{8}$ spores per gram.

\subsection{Substrate preparation and compositional analysis}

Sweet sorghum bagasse was obtained from Suwan Farm, Kasetsart University. This material was thoroughly washed and dried at $65^{\circ} \mathrm{C}$ until constant weight was obtained. The air-dried bagasse was then milled and subsequently sieved to a size of 2-4 mm. The composition of material was then analyzed by the methods of Goering and Van in 1970 [4] to analyse cellulose, hemicellulose, lignin and ash content in the material.

\subsection{Alkali pretreatment}

The sweet sorghum bagasse was soaked with 1, 5, 10 and $15 \%(\mathrm{w} / \mathrm{w}) \mathrm{NaOH}$ solution at a solid to liquid weight ratio of $1: 10$ and consequently autoclaved at $121{ }^{\circ} \mathrm{C}$ for $25 \mathrm{~min}$. The mixture was filtered to separate the solid residues and the filtrate fraction. At the end of the reaction, the solid residues were thoroughly washed with water to remove the residual alkaline until neutral $\mathrm{pH}$ was obtained, then dried at $65{ }^{\circ} \mathrm{C}$, and analyzed the compositions of the solid residues.

\subsection{Optimization of reducing sugar production by acid hydrolysis}

One gram of pretreated material was soaked with $10-30$ gram of $5-55 \%(\mathrm{w} / \mathrm{w})$ sulfuric acid solution in the $250 \mathrm{ml}$ Erlenmeyer flask and then autoclaved at $121^{\circ} \mathrm{C}$ for $40-120$ minutes. After hydrolysis, the suspended material was separated using filter paper. The total reducing sugars in the filtrate were determined by the 3,5-dinitrosalicylic acid (DNS) method described by Miller in 1959 [5].

RSM was applied for the optimization of the reducing sugars production. Three parameters namely concentration of sulfuric acid $\left(X_{1}\right)$, solid to liquid ratio $\left(X_{2}\right)$ and reaction time $\left(X_{3}\right)$ with the ranges of minimum (-1), maximum $(+1)$ and central point $(0)$ were assigned to investigated experimental conditions of reducing sugar production. The levels of parameters for the experimental design are shown in Table 1. 
Table 1. Experimental range and coded levels of factors for reducing sugars production

\begin{tabular}{llcccc}
\hline \multirow{2}{*}{ Factors } & & Symbol & \multicolumn{3}{c}{ Range and levels } \\
\cline { 3 - 6 } & & & -1 & 0 & 1 \\
\hline concentration & $(\% \mathrm{v} / \mathrm{v})$ & $X_{1}$ & 15 & 35 & 55 \\
solid:liquid ratio $(\mathrm{w}: \mathrm{w})$ & $X_{2}$ & $1: 10$ & $1: 20$ & $1: 30$ \\
reaction time & $(\mathrm{min})$ & $X_{3}$ & 40 & 80 & 120 \\
\hline
\end{tabular}

The total of 15 experimental runs with three variables was designed according to a BBD using the statistical software MINITAB release 14. The detailed experimental designs with coded of three parameters are shown in Table 3 . The behavior of the system was explained by the following quadratic model equation which includes the effects of linear, quadratic and interaction was used to determine the predicted response as follows:

$$
Y=\beta_{0}+\beta_{1} X_{1}+\beta_{2} X_{2}+\beta_{3} X_{3}+\beta_{11} X_{1}^{2}+\beta_{22} X_{2}^{2}+\beta_{33} X_{3}^{2}+\beta_{12} X_{1} X_{2}+\beta_{13} X_{1} X_{3}+\beta_{23} X_{2} X_{3}
$$

Where $Y$ is the predicted response, $\beta_{0}$ is the intercept; $\beta_{1}, \beta_{2}$ and $\beta_{3}$ linear coefficient; $\beta_{11}, \beta_{22}$ and $\beta_{33}$ square coefficient; and $\beta_{12}, \beta_{13}$ and $\beta_{23}$ interaction coefficients with $X_{1}, X_{2}$ and $X_{3}$ corresponding to the principal factors of sulfuric acid concentration, solid to liquid ratio and reaction time, respectively

\subsection{Reducing sugar production by microbial hydrolysis}

Reducing sugar production under Solid-State Fermentation (SSF) was conducted in the 250 $\mathrm{ml}$ flask covered with cotton at optimum conditions previously optimized for maximum reducing sugar from pretreated sweet sorghum bagasse by T. harzianum [6]. Each flask containing $5 \mathrm{~g}$ dried pretreated sweet sorghum bagasse, which was used as the carbon source. Standard Mandel medium in $50 \mathrm{mM}$ sodium citrate buffer $(\mathrm{pH} \mathrm{4.8)}$ that contained of $0.3 \mathrm{~g} / 1$ urea, $1.4 \mathrm{~g} / 1\left(\mathrm{NH}_{4}\right)_{2} \mathrm{SO}_{4}, 2.0 \mathrm{~g} / 1 \mathrm{KH}_{2} \mathrm{PO}_{4}, 0.4 \mathrm{~g} / 1 \mathrm{CaCl}_{2} \cdot 2 \mathrm{H}_{2} \mathrm{O}, 0.3 \mathrm{~g} / 1 \mathrm{MgSO}_{4} \cdot 4 \mathrm{H}_{2} \mathrm{O}, 0.75 \mathrm{~g} / 1$ peptone, $0.25 \mathrm{~g} / 1$ yeast extract, $5 \mathrm{~m} \mathrm{~g} / 1 \mathrm{FeSO}_{4} \cdot 7 \mathrm{H}_{2} \mathrm{O}, 1.6 \mathrm{~m} \mathrm{~g} / 1 \mathrm{MnSO}_{4} \cdot 4 \mathrm{H}_{2} \mathrm{O}, 1.4 \mathrm{mg} / 1$ $\mathrm{ZnSO}_{4} \cdot 7 \mathrm{H}_{2} \mathrm{O}$ and $20 \mathrm{mg} / 1 \mathrm{CoCl}_{2} \cdot 6 \mathrm{H}_{2} \mathrm{O}$, was added into the substrate for adjusting initial moisture content $(77.5 \% \mathrm{w} / \mathrm{w})$ before autoclaving at $121{ }^{\circ} \mathrm{C}$ for $20 \mathrm{~min}$. Each flask was inoculated with $10 \%(\mathrm{w} / \mathrm{w})$ fungal spore of $T$. harzianum and incubated at $25^{\circ} \mathrm{C}$ for 88 hours. After suitable periods of time, reducing sugar was extracted from the fermented medium by adding $100 \mathrm{ml}$ distilled water to each flask. The flasks were then shaken at $200 \mathrm{rpm}$ for $2 \mathrm{hr}$ at $60{ }^{\circ} \mathrm{C}$. Suspended solid were separated and the reducing sugars (filtrate) were determined by the DNS method [5]. The composition of reducing sugars (glucose, xylose and arabinose) in hydrolysates was determined by HPLC.

\section{Results and discussion}

\subsection{Chemical composition of substrates}

The main compositions as cellulose, hemicelluloses, lignin and ashes content of sweet sorghum bagasse before and after pretreatment with $1,5,10$ and $15 \%(\mathrm{w} / \mathrm{v})$ of sodium hydroxide are shown in Table 2.

The alkali pretreatment was conducted by pretreating sweet sorghum bagasse at high temperature. When the concentration of sodium hydroxide increased, lignin content was decreased. As a result, the cellulose fraction increased more than $90 \%(\mathrm{w} / \mathrm{w})$ when 10 and $15 \%(\mathrm{w} / \mathrm{v})$ of sodium hydroxide were used. This is typical of alkaline pretreatment, which 
generally has a stronger effect on 1 ignin than cellulose [7]. It was observed that pretreated biomass was swollen, which leaded to the decrease in the degree of polymerization and crystallinity, disruption of the lignin structure, and separation of structural linkages between lignin and carbohydrates [8]. However, the compositions of sweet sorghum bagasse when using 10 and $15 \%(\mathrm{w} / \mathrm{v})$ of sodium hydroxide were not different, so that $10 \%(\mathrm{w} / \mathrm{v})$ of sodium hydroxide was chosen for the pretreatment as the suitable concentration.

Table 2. Main compositions of sweet sorghum bagasse in untreated bagasse and after alkaline pretreatments

\begin{tabular}{cccrrr}
\hline \multirow{2}{*}{$\begin{array}{c}\text { Composition } \\
\text { (\%dry weight) }\end{array}$} & \multicolumn{5}{c}{$\mathrm{NaOH}$ concentration $(\% \mathrm{w} / \mathrm{v})$} \\
\cline { 2 - 6 } & Untreated & 1 & 5 & 10 & 15 \\
\hline bagasse & 58.23 & 68.66 & 86.18 & 90.37 & 91.10 \\
Hellulose & 25.42 & 19.28 & 9.70 & 5.97 & 5.82 \\
Lignicellulose & 14.95 & 12.02 & 3.97 & 3.56 & 2.97 \\
Ash & 1.40 & 0.04 & 0.15 & 0.10 & 0.11 \\
\hline
\end{tabular}

\subsection{Optimization of reducing sugar production by acid hydrolysis}

In the present study, BBD was used to investigate the optimal conditions of the reducing sugar production from pretreated bagasse. There were three factors namely concentration of sulfuric acid, solid to liquid ratio and reaction time and three levels of each parameter were varied as shown in Table 3.

Table 3. Reducing sugar from pretreated bagasse in experiments obtained by Box-Behnken design

\begin{tabular}{ccccc}
\hline & \multicolumn{3}{c}{ Level of experimental factors } & \\
\cline { 2 - 4 } Run number & $\begin{array}{c}\text { Concentration } \\
\left(X_{1}\right)\end{array}$ & $\begin{array}{c}\text { Solid to liquid } \\
\text { ratio }\left(X_{2}\right)\end{array}$ & $\begin{array}{c}\text { Reaction } \\
\text { time }\left(X_{3}\right)\end{array}$ & $\begin{array}{c}\text { Reducing sugar } \\
(\% \mathrm{~g} / \mathrm{g} \text { dry weight })\end{array}$ \\
\hline 1 & -1 & -1 & 0 & 28.46 \\
2 & 1 & -1 & 0 & 16.90 \\
3 & -1 & 1 & 0 & 24.99 \\
4 & 1 & 1 & 0 & 6.53 \\
5 & -1 & 0 & -1 & 23.06 \\
6 & 1 & 0 & -1 & 13.01 \\
7 & -1 & 0 & 1 & 27.35 \\
8 & 1 & 0 & 1 & 7.75 \\
9 & 0 & -1 & -1 & 25.81 \\
10 & 0 & 1 & -1 & 18.09 \\
11 & 0 & -1 & 1 & 20.36 \\
12 & 0 & 1 & 1 & 12.24 \\
13 & 0 & 0 & 0 & 31.11 \\
14 & 0 & 0 & 0 & 29.81 \\
15 & 0 & 0 & 0 & 29.92 \\
\hline
\end{tabular}

The fifteen experiments were designed as shown in Table 3 and the maximum reducing sugar is $31.11 \%$ ( $\mathrm{g} / \mathrm{g}$ dry substrate), which was observed at the experimental run number 13 . The statistical software MINITAB release 14 was used to design of experiments, to determine the 
coefficients of linear, quadratic and interaction terms, and to build the quadratic model and response surface plots.

The BBD was used to investigate the effects of the assigned parameters on the reducing sugar production. The experimental results were analyzed by regression analysis consisting of the effect of linear, quadratic and interaction which gave the following regression equation with reducing sugar production as a function of concentration of sulfuric acid $\left(X_{1}\right)$, solid to liquid ratio $\left(X_{2}\right)$ and reaction time $\left(X_{3}\right)$. Reducing sugar $(Y)$ at specific combination of three variables can be predicted by substituting the corresponding values of each variable in Eq. (2).

$$
\begin{aligned}
Y= & -24.5581+1.1226 X_{1}+1.1375 X_{2}+0.7000 X_{3}-0.0155 X_{1}{ }^{2}-0.0175 X_{2}{ }^{2} \\
& -0.0039 X_{3}{ }^{2}-0.0030 X_{1} X_{3}
\end{aligned}
$$

The probability value ( $p$-value) is a tool for evaluating the significance and contribution of each parameter and the statistical polynomial model equation. The smaller $p$-value is an indication of high significance of corresponding coefficient [9]. The regression coefficient in the response surface model for the linear, quadratic and interaction effects of the variables are shown along with $p$-value in Table 4 . The $p$-value suggested that the coefficient for the linear effect of sulfuric acid concentration $(p<0.01)$, solid to liquid ratio $(p<0.01)$ and reaction time $(p<0.01)$ were statistically significant for reducing sugar production.

Table 4. Estimated regression coefficient and corresponding p-value for reducing sugar production

\begin{tabular}{ccc}
\hline Term & Coefficient & $p$-value \\
\hline Constant & -24.5581 & $0.027^{*}$ \\
$X_{1}$ & 1.1226 & $0.003^{* *}$ \\
$X_{2}$ & 1.1375 & $0.007^{* *}$ \\
$X_{3}$ & 0.7000 & $0.001^{* *}$ \\
$X_{1}{ }^{2}$ & -0.0155 & $0.001^{* *}$ \\
$X_{2}{ }^{2}$ & -0.0175 & $0.003^{* *}$ \\
$X_{3}$ & -0.0039 & $0.001^{* *}$ \\
$X_{1} X_{2}$ & -0.0052 & 0.102 \\
$X_{1} X_{3}$ & -0.0030 & $0.039^{*}$ \\
$X_{2} X_{3}$ & -0.0001 & 0.913 \\
\hline
\end{tabular}

$* p<0.05, * * p<0.01$

Analysis of variance (ANOVA) for proposed model is shown in Table 5. The $p$-value of the regression model $(p<0.001)$ implies that the model is significant. In addition, the coefficient of variation $\left(R^{2}=0.986\right)$ indicates a high correlation between the observed and predicted values from model Eq. (2). Therefore, this equation can be used for predicting the amount of reducing sugar production under parameter ranges of assigned three variables. 
Table 5. Analysis of variance (ANOVA) for reducing sugar production

\begin{tabular}{cccccc}
\hline Source & $\begin{array}{c}\text { Degree of } \\
\text { Freedom (DF) }\end{array}$ & $\begin{array}{c}\text { Sum of } \\
\text { square } \\
(\mathrm{SS})\end{array}$ & $\begin{array}{c}\text { Mean } \\
\text { square (MS) }\end{array}$ & F & $p$-value \\
\hline Regression model & 9 & 2024.63 & 224.959 & 38.49 & 0.000 \\
Residual Error & 5 & 29.22 & 5.844 & & \\
Total & 14 & 2053.85 & & & \\
\hline$R^{2}=98.6 \% \quad R^{2}(\mathrm{adj})=96.0 \%$ & & & &
\end{tabular}

The two-dimensional (2D) contour plots and three-dimensional (3D) response surface of the interactions are presented in Figure 1, 2 and 3. These observations also identified the optimal conditions with the maximum response for the levels of the factors in the design of experiments. The maximum response is referred to the surface confined in smallest ellipse in the contour plot. The perfect interaction between the independent variables can be shown when elliptical contours are obtained [9].
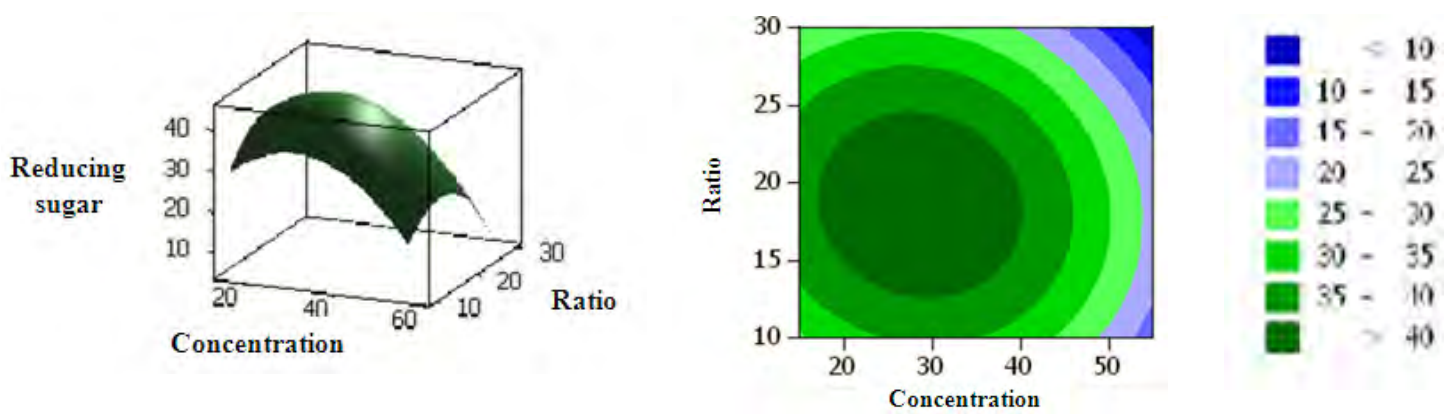

Fig. 1. Contour plot and response surface for the effects of acid concentration and solid to liquid ratio at a constant reaction time (80 minutes).
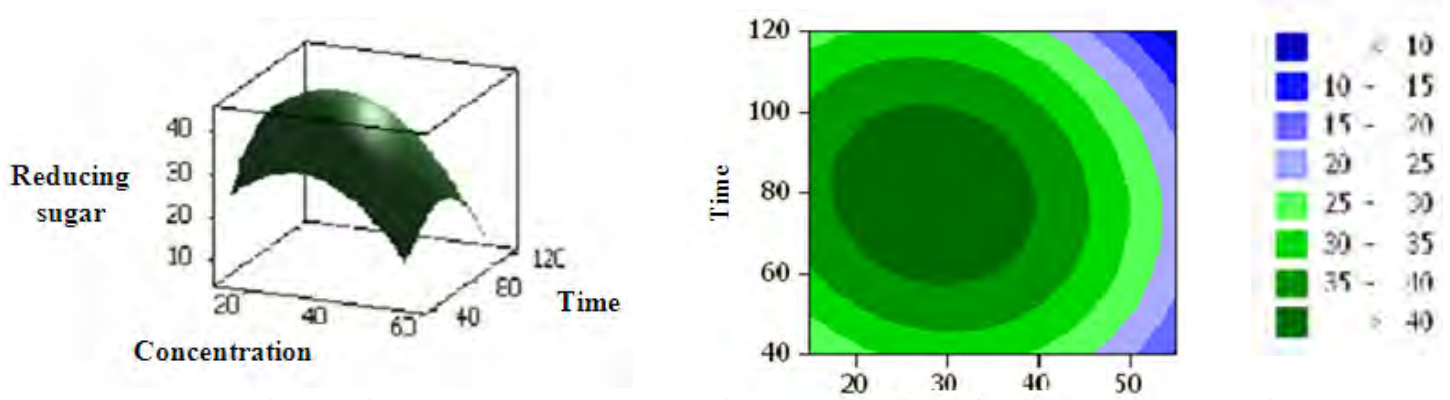

Fig. 2. Contour plot and response surface for the effects ofcacidentration and reaction time at a constant solid to liquid ratio $(1: 20)$.
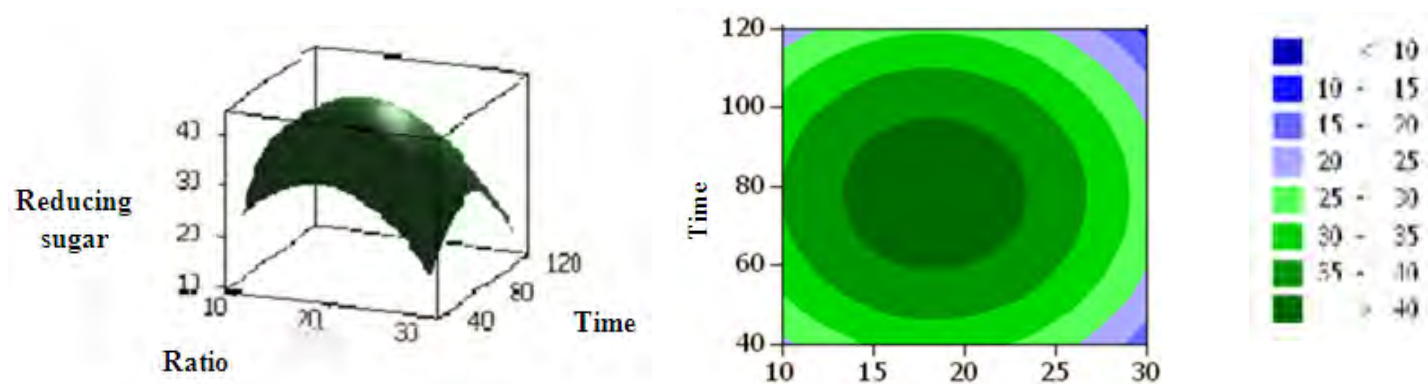

Fig. 3. Contour plot and response surface for the effects of solid to liquid ratio and reaction time at a constant acid concentration $(35 \% \mathrm{v} / \mathrm{v})$. 
Application of RSM with BBD predicted that the maximum reducing sugar production must occur at decoded values of condition parameters at sulfuric acid of $21.44 \%(\mathrm{v} / \mathrm{v})$, solid to liquid ratio of 1:12.5 and reaction time of 73.24 minutes. At this maximum condition, the reducing sugar should reach $34.97 \%$ (g/g dry substrate). A repeat acid hydrolysis for reducing sugar production under optimal conditions is carried out to confirm the prediction. After performing the hydrolysis under optimal condition, the obtained reducing sugar is $33.49 \%$ (g/g dry substrate). Since the difference between predicted and actual confirmed result was only about $4.23 \%$, it should be regarded as acceptable.

\subsection{Reducing sugar production by microbial hydrolysis}

In this respect, preatreated sweet sorghum bagasse was conducted for the production of reducing sugar by $T$. harzianum under SSF. An inoculum $(10 \% \mathrm{w} / \mathrm{w})$ was added to a medium of $77.5 \%(\mathrm{w} / \mathrm{w})$ moisture content and incubated at $25^{\circ} \mathrm{C}$ for 84 hours. Reducing sugar was expressed based on weight of dry substrate and carried out in triplicates and standard deviation was less than $6 \%$. As shown in Figure 4, the highest reducing sugar, $10.34 \%(\mathrm{w} / \mathrm{w})$, was obtained at 56 hours of fermentation time. The conditions used in the experiment were the optimum conditions previously studied [6].

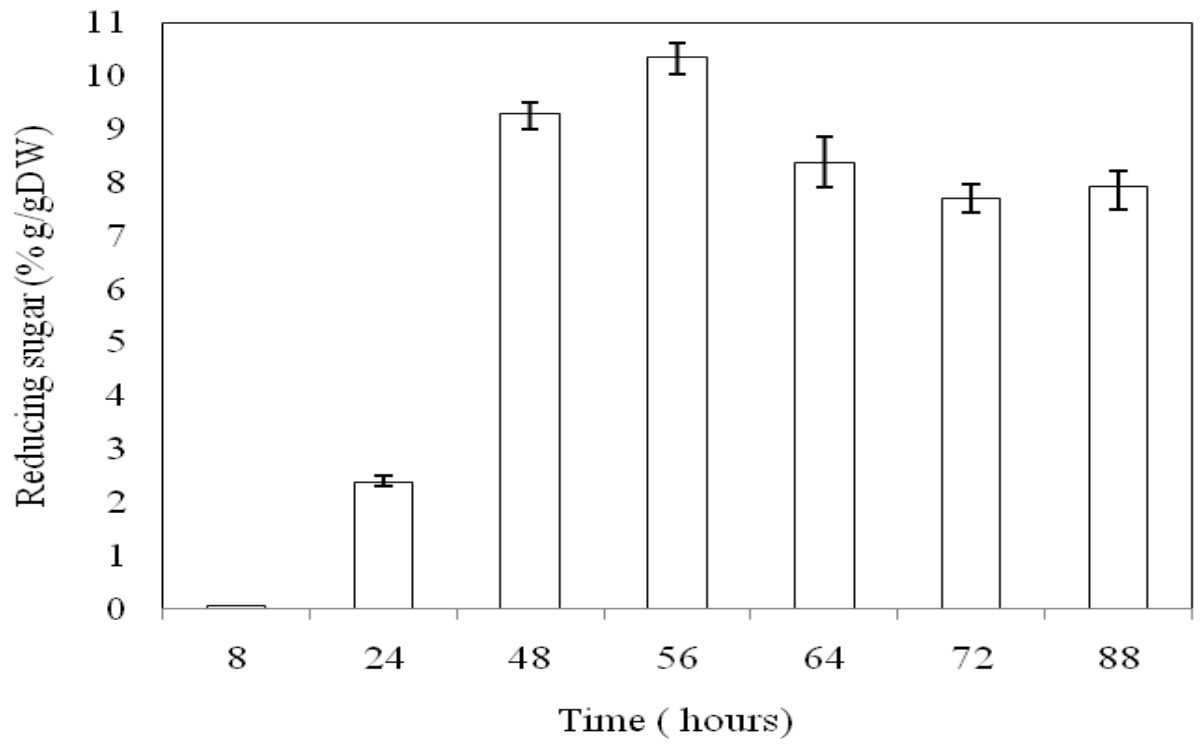

Fig. 4. Reducing sugar production by T. harzianum under SSF using pretreated sweet sorghum bagasse as the substrate (inoculum of $10 \% \mathrm{w} / \mathrm{w}$ and moisture content of $77.5 \% \mathrm{w} / \mathrm{w}$ )

The reducing sugar obtained from acid hydrolysis $(33.49 \%)$ was higher than from microbial hydrolysis $(10.34 \%)$ because the conditions of chemical hydrolysis are stronger than microbial hydrolysis. However, acid hydrolysis has several disadvantages over microbial hydrolysis due to formation of toxic compounds, such as furfural, hydroxylmethylfurfural, acetic acid, formic acid, levulinic acid etc. These toxic compounds can inhibit the yeast fermentation in next step of ethanol production. Removal of these compounds increases the additional costs for ethanol production [10].

The advantages of microbial hydrolysis include low energy requirement, mild conditions and the ready sugar for further fermentation. However, the rate of hydrolysis in most microbial hydrolysis processes is very low. 


\section{Conclusions}

The optimal conditions obtained through a statistical Box-Behnken Design are successfully determined to maximize the reducing sugar production from acid hydrolysis. The result from the second order polynomial model developed indicated that the optimal conditions for reducing sugar production from pretreated sweet sorghum bagasse by sulfuric acid hydrolysis are $21.44 \%(\mathrm{v} / \mathrm{v})$ of sulfuric acid, solid to liquid ratio of $1: 12.5$ and reaction time of 73.24 minutes which give the maximum reducing sugar of $33.49 \%$ (g/g dry substrate) higher than the maximum reducing sugar of microbial hydrolysis $(10.34 \% \mathrm{~g} / \mathrm{g}$ dry substrate).

\section{Acknowledgements}

This study was supported by Kasetsart University Reseach and Development Institute (KURDI), Department of Chemical Engineering, Faculty of Engineering, Kasetsart University, Thailand and The Center of Excellence for Petroleum, Petrochemicals and Advanced Materials, S\&T Postgraduate Education and Research Development Office (PERDO).

\section{References}

[1] D. Mamma, P. Christakopoulos, D. Koullas, D. Kekos, B.J. Macris and E. Koukios, An alternative approach to the bioconversion of sweet sorghum carbohydrates to ethanol, Biomass and Bioenergy 8, 1995, pp. 99-103.

[2] S. Carmen, Lignocellulosic residue: Biodegradation and bioconversion by fungi, Biot. Adv 27, 2009, pp. 185-194.

[3] R. Aguilar, J.A. Ramirez, G. Garrote, and M. Vazquez, Kinetic study of acid hydrolysis of sugarcane bagasse, J. Food Eng 55, 2002, pp. 309-318.

[4] H.K. Goering and P.J. Van, Forage fibre analysis Agriculture handbook, Agricultural Research Services, 1970, pp. 20.

[5] G.L. Miller, Analytical Chemistry 31, 1959, pp. 426-428.

[6] K. Vuttibunchon, Box-Behnken experimental design of reducing sugar production from sweet sorghum bagasse by Trichoderma harzianum, M.S.Thesis (Thai), Kasetsart University, 2010.

[7] J.M. Gould, Studies on the mechanism of alkaline peroxide delignification of agricultural residues, Biotechnol. Bioeng 27, 1985, pp. 225-231.

[8] L.T. Fan, M.M. Gharpuray, and Y.H. Lee, In: Cellulose hydrolysis Biotechnology Monograph, Springer Berlin 57, 1987, pp. 211.

[9] A. Md. Zahangir, A. M. Suleyman and W. Rosmaziah, Statistical optimization of process conditions for cellulase production by liquid state bioconversion of domestic wastewater sludge, Bioresource Technology 99, 2008, pp. 4709-4716.

[10]E. Palmqvist and B. Hahn-Hagerdal. Fermentation of lignocellulosic hydrolysates. I: inhibition and detoxification, Bioresource Technology 74, 2002, pp. 17-24. 